\title{
Multiple martensitic transformation induced by coherent precipitation in NiTiCo melt spun ribbons
}

\author{
Ph. Vermaut ${ }^{1,2}$, M. Larnicol ${ }^{2}$, M. Hÿtch ${ }^{1}$, P. Ochin ${ }^{1}$ and R. Portier ${ }^{1,2}$ \\ ${ }^{1}$ Centre d'Études de Chimie Métallurgique, UPR 2801 du CNRS, 15 rue Georges Urbain, \\ 94407 Vitry-sur-Seine, France \\ ${ }^{2}$ Laboratoire de Métallurgie Structurale, École Nationale Supérieure de Chimie de Paris, \\ 11 rue Pierre et Marie Curie, 75231 Paris, France
}

\begin{abstract}
A study of a multiple martensitic transformation observed in melt spun ribbons cast with a relatively low melt temperature is presented. Transmission electron microscope (TEM) investigations allow the identification of fine plate-like precipitates as a metastable $\mathrm{Ti}_{2} \mathrm{Ni}$ phase. Analysis of high resolution microscope (HREM) images reveals the presence of a strain field in the matrix surrounding the precipitates which promote the martensitic transformation. Grow and loss of coherency of these precipitates coincides with disappearance of the higher temperature martensitic transformation. Attribution of the multiple transformation to this precipitation is discussed.
\end{abstract}

\section{INTRODUCTION}

Rapid solidification is a powerful and original elaboration process, which allows semi-finished products to be obtained directly and thus saves on thermomechanical treatments [1]. It is also well known that this process leads to fine-scale microstructures, and in some cases, to amorphous and other metastable phases [2].

NiTi alloys are well known for their excellent shape memory properties due to a thermoelastic martensitic transformation. The transformation temperature (Ms) is very sensitive to the alloy composition and microstructure. Multiple martensitic transformations can occur in shape memory alloys for several reasons. Their origin can be attributed to the appearance of two different kinds of martensite [3] or to some microstructures such as a bimodal grain size distribution after crystallization of the partly amorphous ribbons [4]. This transformation temperature can also be locally modified inside a grain because of the presence of dislocations walls [5] or coherent precipitation [6], which can either promote the transformation or can act as a barrier.

In the present study, multiple martensitic transformations are observed on differential scanning calorimetry (DSC) curves of NiTiCo melt spun ribbons, as a function of the melt temperature before ejection onto the wheel and heat treatment temperature. The aim of the present work is to correlate this phenomenon to a very thin and coherent precipitation observed in the ribbons and to fully characterize them by transmission electron microscopy (TEM).

\section{EXPERIMENTAL}

$1 \mathrm{~cm} \times 50 \mu \mathrm{m}$ ribbons of $\mathrm{NiTi}$ and $\mathrm{Ni}_{47} \mathrm{Ti}_{50} \mathrm{Co}_{3}$ alloys were produced by melt spun technique under helium atmosphere, with a melt temperature before ejection onto the wheel ranging from 1420 to 1500 ${ }^{\circ} \mathrm{C}$. A steel wheel rotating with a linear speed of $19 \mathrm{~m} / \mathrm{s}$ was used for all castings with ejection pressure of $200 \mathrm{hPa}$.

Heat treatments were carried out in a vacuum furnace with a pressure lower than $5.10^{-6}$ torr. Characteristics of the martensitic transformation were determined by DSC measurements on a Mettler TA4000 calorimeter at a $10^{\circ} \mathrm{C} / \mathrm{mn}$ scan rate. Microstructural analysis was carried out by TEM on a Jeol $2000 \mathrm{FX}$ and a high resolution Topcon 002B electron microscopes operating at $200 \mathrm{kV}$ and equipped with a Kevex X-ray Energy Dispersion Spectroscopy (EDS) detector. Thin foils were obtained by twin jet electropolishing in a $6 \%$ Perchloric acid in acetic acid solution at $14^{\circ} \mathrm{C}$. 


\section{RESULTS AND DISCUSSION}

\subsection{Martensitic transformation}

The influence of rapid solidification parameters on $\mathrm{Ni}_{50} \mathrm{Ti}_{50} \mathrm{Co}_{\mathrm{x}}(\mathrm{x}=2,3)$ alloy properties has already been studied in previous work [7-8]. DSC curves of the as-quenched $\mathrm{Ni}_{47} \mathrm{Ti}_{50} \mathrm{Co}_{3}$ ribbons, obtained for different quenching temperatures, are shown on figure $1 \mathrm{a}$ and $\mathrm{b}$ and compared with the bulk alloy. A decrease of the $\mathbf{R}$-phase to martensite transformation temperatures is observed on the cooling curves for increasing quenching temperature, whereas that of the austenite to $\mathrm{R}$-phase remains approximately constant. The difference between the temperatures of these two transformations is so large that they remain separate on the heating curves.

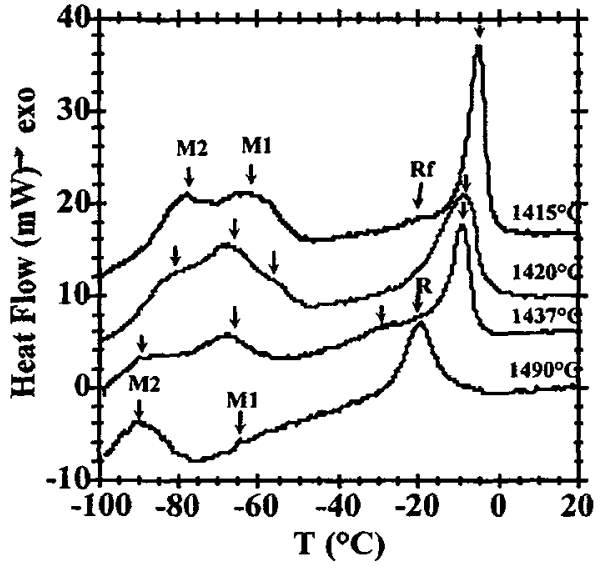

a) Cooling

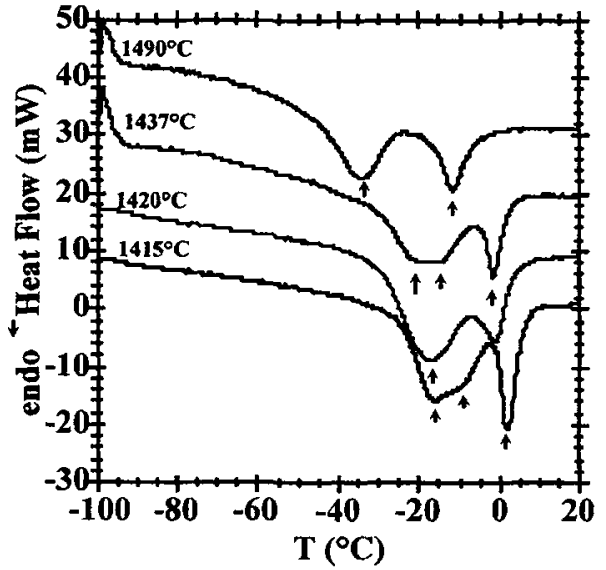

b) Heating

Figure 1 : DSC curves of as-quenched $\mathrm{Ni}_{4} \mathrm{Ti}_{50} \mathrm{Co}_{3}$ ribbons for different quenching temperatures.

Cooling curves of ribbons quenched at $1415,1420,1437$ and $1490^{\circ} \mathrm{C}$ exhibit broad martensitic transformation peaks with two or three maxima, meaning that they are two or three-stage martensitic transformations. Two principal martensitic transformations can be identified (see figure la and b), one at higher temperature, named $\mathrm{M} 1$, and a second one at lower temperature, named M2. Similar multiple martensitic transformations have been observed in melt spun ribbons for other compositions [9].

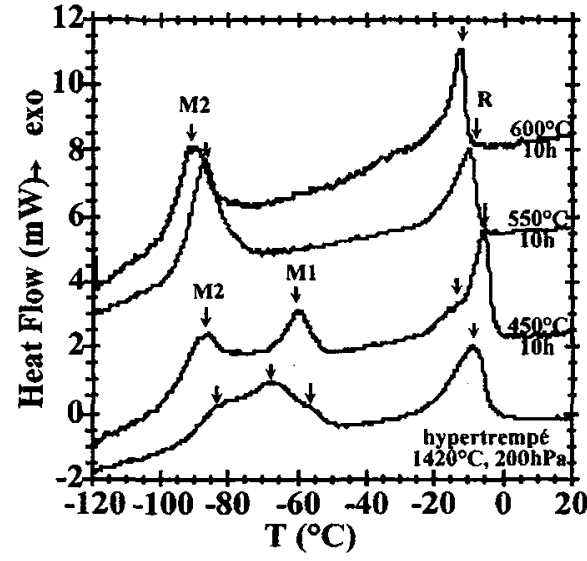

a) Cooling

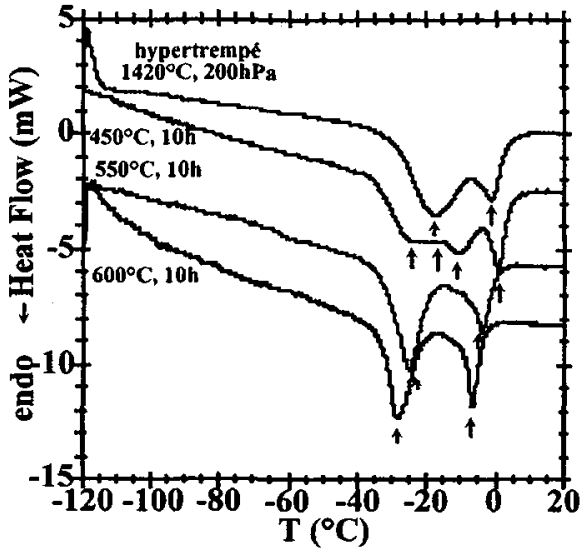

b) Heating

Figure 2 : Influence of heat treatments on the DSC curves of $\mathrm{Ni}_{4} 7^{\mathrm{Ti}} \mathrm{T}_{50} \mathrm{Co} 3$ ribbon quenched from $1420^{\circ} \mathrm{C}$

Figures $2 \mathrm{a}$ and $2 \mathrm{~b}$ show the evolution of the DSC curves for the $\mathrm{Ni}_{47} \mathrm{Ti}_{50} \mathrm{Co}_{3}$ ribbons quenched from $1420^{\circ} \mathrm{C}$ as a function of the heat treatment temperature. After a $10 \mathrm{hrs}$ annealing at $450^{\circ} \mathrm{C}$, a two stage 
martensitic transformation is clearly visible with two well defined $\mathrm{M} 1$ and $\mathrm{M} 2$ peaks which have similar intensities and are separated by approximately $30^{\circ} \mathrm{C}$. After annealing at $550^{\circ} \mathrm{C}$ and higher temperatures, only one of the two martensitic peaks remains. This peak, which presents a strong intensity, similar to that of the R-phase peak, occurs at a low temperature corresponding to that of the previous M2 peak. The M1 peak which corresponds to a higher temperature martensite transformation is no longer visible.

\subsection{Microstructure}

TEM observations were carried out on the as-quenched and the annealed ribbons. At room temperature, all the samples exhibit a highly $[001]_{\mathrm{B} 2}$ textured austenitic microstructure. $\mathrm{Ti}_{2} \mathrm{Ni}$ precipitation occurs at grain boundaries but also inside the grains as small incoherent and spherical $10 \mathrm{~nm}$ diameter particles. Their density increases with the quenching temperature of the ribbon, and probably lead to an enrichment in nickel of the surrounding matrix in accordance with the slight decrease of the transformation
temperatures (fig.1).

In addition to these $\mathrm{Ti}_{2} \mathrm{Ni}$ particles, a fine coherent precipitation is also observed inside the austenite grains. This latter precipitation is coherent only in the as-quenched samples annealed at $450^{\circ} \mathrm{C}$. In samples annealed at $550^{\circ} \mathrm{C}$ or higher, the precipitates grow and lose their coherency. From these observations, a strong correlation can be supposed between the coherency of this precipitation and the multiple martensitic transformation visible on the DSC curves. A similar correlation is witnessed in
samples with and without Co.

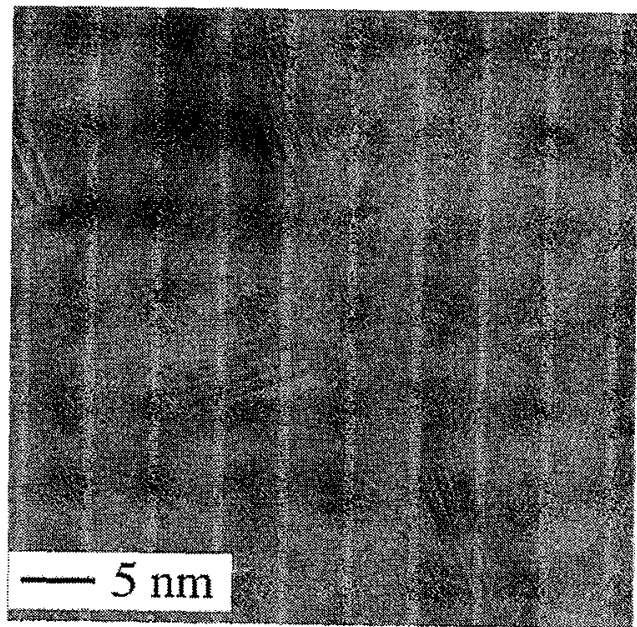

a)

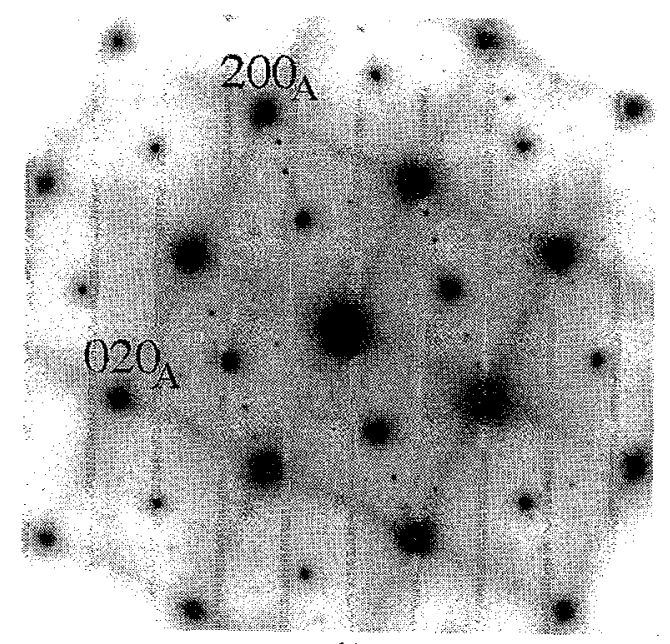

b)

Figure 3 : a) Image of an austenite grain with precipitates taken along the [001] direction (the reproduction does not allow the lattice fringes in the matrix to be seen), moiré fringes are seen in the precipitates b) corresponding selected area diffraction pattern showing extra spots due to the precipitates.

A typical high-resolution electron microscope image of these precipitates is shown on figure 3 where the additional contrast seen in the precipitates is due to moire interference. They are plate-like precipitates parallel to the $\{001\}_{\text {B2 }}$ planes. Only two of the three different variants are visible on figure $3 \mathrm{a}$. The third variant, perpendicular to the direction of observation, has a square shape (figure 4). After $10 \mathrm{hrs}$ at $450^{\circ} \mathrm{C}$, the extra spots due to and then diffraction patterns of a single particle can be recorded (figure $5 \mathrm{a}$ and $\mathrm{b}$ ). The extra spots due to the precipitate are coherent with the diffraction pattern of a face centered cubic structure observed along the $[110]$ direction. The lattice parameter is then $a_{B 2} \times \sqrt{2}$ and the orientation relationship are : $[100]_{\mathrm{B} 2} / /[110]_{\mathrm{FCC}}$ and $(001)_{\mathrm{B} 2} / /(001)_{\mathrm{FCC}}$.

The extra spots visible on figure $3 b$ can be explained by variants 1 and 2 . Diffraction spots due to the third variant merges with those of the matrix. A diffraction pattern recorded after a tilt of $35^{\circ}$ from $[001]_{\mathrm{B} 2}$ toward $[010]_{\mathrm{B} 2}$ is presented on figure $6 \mathrm{a}$. The diffraction spots of the 3 different variants and the
$\mathrm{B} 2$ structure are represented on figure $6 \mathrm{~b}$ showing the orientation relation. 


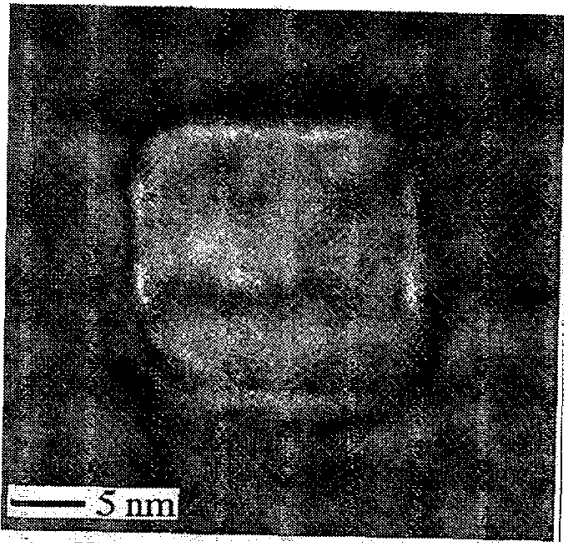

$\mathrm{X}$-ray microanalysis has been performed on samples aged at $450^{\circ} \mathrm{C}$ for $10 \mathrm{hrs} .20 \mathrm{~nm}$ wide plates were selected and a $10 \mathrm{~nm}$ diameter probe was used. Quantification results indicate a composition close to $\mathrm{Ti}_{2} \mathrm{Ni}$. However, the diffraction patterns of figure $5 \mathrm{~b}$ and 6 do not correspond to those of the well known cubic $\mathrm{Ti}_{2} \mathrm{Ni}$ phase with a lattice parameter $\mathrm{a}=11.28 \AA$ and no simple relationship could be found between the two structures. Coherent precipitation of $\mathrm{Ti}_{2} \mathrm{Ni}$ have already been observed in Ti-rich sputtered thin films [10]. However, in that case, they present the equilibrium structure and cube to cube orientation relationships.

Figure 4 : High resolution image of the precipitate plate parallel to the thin foil showing their square shape.

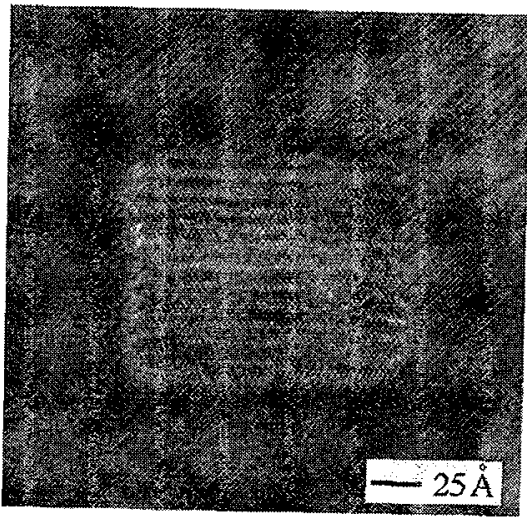

a)

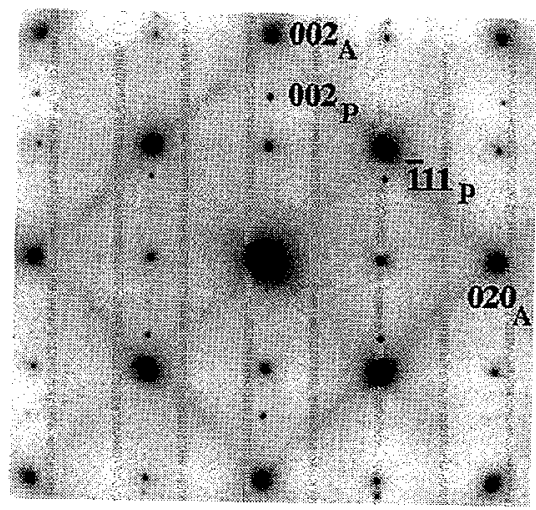

b)

Figure $5:$ a) High resolution image of a precipitate after $10 \mathrm{hrs}$ at $450^{\circ} \mathrm{C}$ annealing with b) selected area diffraction pattern. Extra spots due to the precipitate are coherent the diffraction pattern of a FCC structure observed along the [110] direction.

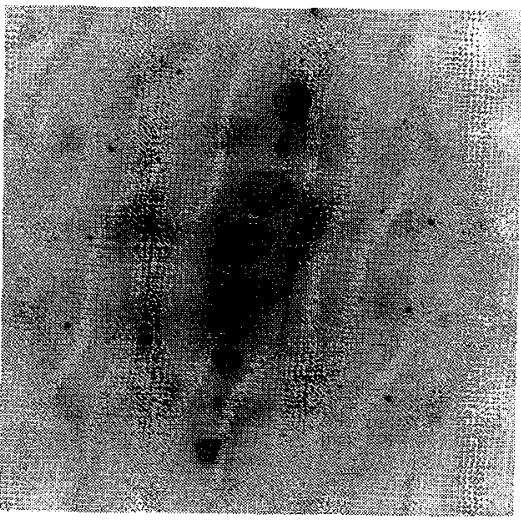

a)

$$
\begin{aligned}
& \mathrm{OAZ}=[111]_{\mathrm{v}} \\
& \diamond \mathrm{AZ}=|\overline{1} \mathrm{j} 2|_{\mathrm{V} 2} \\
& \mathrm{~A} \mathrm{AZ} \sim|150|_{\mathrm{V} 3}
\end{aligned}
$$

Dble diff $\triangle \mathrm{h} 0 \mathrm{O}_{\mathrm{B} 2}$

Figure 6 : a) Selected area diffraction pattern recorded after a tilt of $35^{\circ}$ from [001]B2 to the three variants are visible. b) Schematic representation of the diffraction patterns. 


\subsection{Correlation between precipitation and multiple martensitic transformation}

Precipitation can modify the chemistry and/or induces a strain field in the surrounding matrix. In the present case, the precipitates should induce a Ni enrichment of the matrix. Since the Ni content of the alloy is 50 at\%, such kind of enrichment should induce a strong decrease of the transformation temperature of the precipitates surrounding matrix. This conclusion is not compatible with the position of the M2 peak on the DSC curves (figure 3) which is attributed to the presence of the precipitates. Moreover, it has been argued that such chemical effects only induce an enlargement of the transformation peaks on DSC curves but do not give rise to multiple transformations with well separated peaks [11].

HREM was carried out in order to study the strain state of the matrix around the precipitates. An image obtained in a as-spun sample quenched at $1420^{\circ} \mathrm{C}$, and analyzed using the geometric phase technique [12, 13], is shown on figure 7. The technique consists in calculating the local Fourier components corresponding to the individual lattice fringes which constitute the image. The phase of the local Fourier component is then directly related to the component of the displacement field in the direction of $\mathrm{g}$, the reciprocal lattice vector associated with the fringes analyzed. By combining the phase from two sets of lattice fringes, the 2-dimensional displacement field can be determined [12].

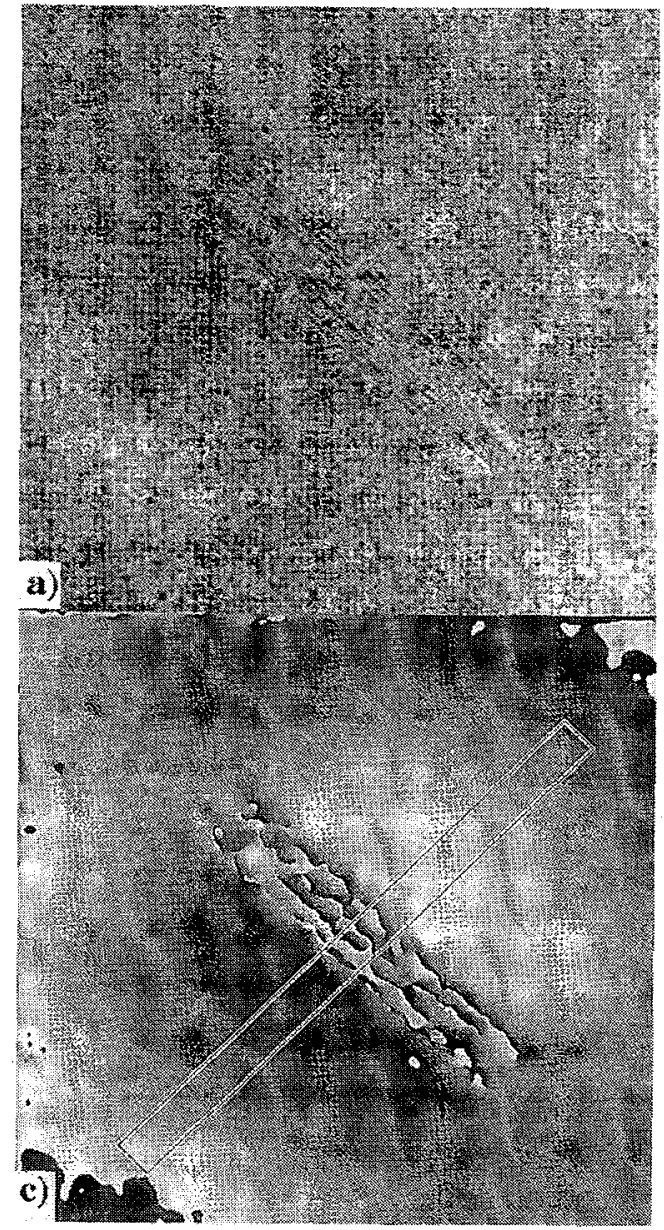

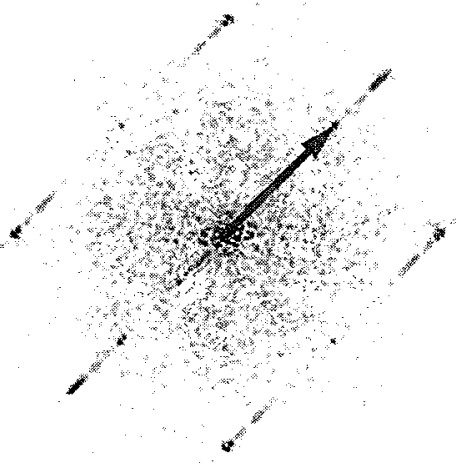

b)

$$
\mathrm{g}_{1}=100_{\mathrm{A}}
$$

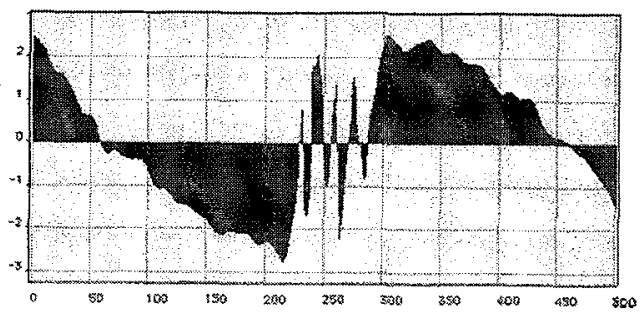

d)

Figure $7:$ a) High resolution image of a precipitate plate parallel to the electron beam observed in a as spun sample. b) Fourier transform of the HREM image c) component of the displacement field in the direction of g1 d) profil of the component of the displacement $* 2 \pi * g 1$

Such analysis have been carried out on the HREM image shown on figure $7 \mathrm{a}$. Its fourier transform is given figure $7 \mathrm{~b}$. Figure $7 \mathrm{c}$ and $d$ shows the component of the displacement field in the [100] direction 
corresponding to the (100) lattice fringes of the matrix (parallel to the precipitate plate) and its profile across the precipitate plate. Indeed, the phase corresponding to the (010) lattice fringes shows very little variation and thus the displacement field is almost entirely in the [100] direction, perpendicular to the precipitate. The gradient visible on both sides of the precipitate indicate presence of a strong and symmetrical displacement field. On the dark side of the precipitate, the displacement is negative : the fringes are displaced away of the precipitate. On the bright side, the displacement is positive meaning that the fringes are still displaced away of the precipitate. As a consequence, a shear of these lattice planes is clearly pointed out, which probably promote the martensite transformation on the corner of the precipitate plates and thus give the M1 peak on the DSC curves (figure 2a). Far from the precipitates, the martensite appear for a lower temperature giving the M2 peak.

In samples annealed at $550^{\circ} \mathrm{C}$ and higher, the precipitates grow, their shape become more spherical meaning that they lose their coherency. The strain field induced in the surrounding matrix is relaxed by presence of dislocations at the matrix/precipitate interface. As a consequence, the M1 peak of the DSC curves disappear.

\section{CONCLUSION}

Multiple martensitic transformations have been observed to occur in melt spun ribbons quenched from temperatures lower than $1490^{\circ} \mathrm{C}$. Heat treatments at temperatures equal and lower than $450^{\circ} \mathrm{C}$ emphasize the separation between the two martensitic transformations, whereas heat treatments at higher temperatures suppress the higher temperature transformation. A good correlation between the multiple martensitic transformation and presence of plate-like coherent precipitates is observed. Analysis of the strain field in the matrix surrounding the precipitates confirm this observation. TEM analysis of the precipitates allow us to identify a new state of the $\mathrm{Ti}_{2} \mathrm{Ni}$ phase.

\section{Acknowledgments}

The authors would like to thank A. Dezellus and Ph. Plaindoux for ribbons casting. This work was partly supported by EEC INCO-Copernicus project IC15-CT96-0704.

\section{References}

[1] A. L. Greer, Mat. Sci. and Eng. A, 113 (1991) 16.

[2] N. M. Matveeva, V. A. Lobodyuk, V. A. Kolomytsev, I. D. Lovzova, Izvestiya Academy of Science USSR, Metals, 4 (1991) 164

[3] Y. C. Lo, S. K. Wu, H. E. Horng, Acta Met., 41 (1993) 747.

[4] L. Litynska, P. Vermaut, J. Morgiel, J. Dutkiewicz, P. Ochin, and R. Portier, this proceedings.

[5] H. Morawiec, J. Ilczuk, D. Stroz, T. Goryczka, D. Chrobak, in Proceedings of the IVth European Symposium on martensitic transformations, Enschede, 1997, edited by J. Beyer, A. Böttger, J. H. Mulder (EDP Sciences, Les Ulis 1997), p. 155.

[6] L. Bataillard, R. Gotthardt, J. de Physique IV, 5 C8 (1995) 647.

[7] M. Larnicol, R. Portier, P. Ochin, in Proceedings of the IVth European Symposium on martensitic transformations, Enschede, 1997, edited by J. Beyer, A. Böttger, J. H. Mulder (EDP Sciences, Les Ulis 1997), p. 191.

[8] C. Elgoyhen, M. Larnicol, P. Ochin, and R. Portier, J. Phys. IV France 10 (2000) Pr6-21.

[9] M. Larnicol, PhD thesis, Paris-sud University, France (1998) 168.

[10] A. Ishida, K. Ogawa, M. Sato, and S. Miyazaki, Met. and Mat. Trans. A, 28 (1997) 1985.

[11] L. Bataillard, PhD thesis, EPFL, Switzerland (1996).

[12] M. Hÿtch, E. Snoeck, R. Kilaas, Ultramicroscopy, 74 (1998) 131.

[13] M. Hÿtch, Ph. Vermaut, J. Malarria, R. Portier, Mat. Sci. Eng. A, 273-275 (1999) 266. 